\title{
Impaired IgA response to Giardia heat shock antigen in children with persistent diarrhoea and giardiasis
}

\author{
S Char, A M Cevallos, P Yamson, P B Sullivan, G Neale, M J G Farthing
}

Department of

Bartholomew's Hospital,

London

$S$ Char

A $M$ Cevallos

P Yamson

M J G Farthing

Dunn Nutrition

Laboratory, University of

Cambridge, Cambridge

P B Sullivan

G Neale

Correspondence to:

Professor M J G Farthing,

Department of

Gastroenterology,

St Bartholomew's Hospital,

West Smithfield, London

EClA 7BE.

Accepted for publication

12 June 1992
Gastroenterology, St

\begin{abstract}
The serum antibody response in Gambian children with persistent diarrhoea and giardiasis has been studied. Total serum IgG, IgA, and IgM concentrations were increased in these patients as compared with controls from the same area. Determination of the concentrations of Giardia specific antibodies by enzyme linked immuno adsorbent assay (ELISA), however, revealed that only IgM was raised while those of $\operatorname{IgA}$ and IgG were similar to the controls. Analysis of the antigenic determinants of the IgG and IgA responses by immunoblotting showed that patients with chronic infection unlike those who clear the infection have no $\mathrm{IgA}$ response to a $57 \mathrm{kDa}$ Giardia heat shock antigen. The association of high concentrations of Giardia specific IgM, low concentrations of Giardia specific IgA and IgG and inability to clear the infection suggests that the switch from an IgM to an IgG or IgA response is inefficient.

(Gut 1993; 34: 38-40)
\end{abstract}

Giardia lamblia produces a wide spectrum of infection in man ranging from asymptomatic carriage through acute to persistent diarrhoea with intestinal malabsorption. Host factors are thought to be important in determining the severity of the response to this parasite. Both humoral and cellular immune responses are important in clearing the parasite and providing immunity. Immunocompromised individuals, notably those with hypogammaglobulinaemia and human immunodeficiency virus infection

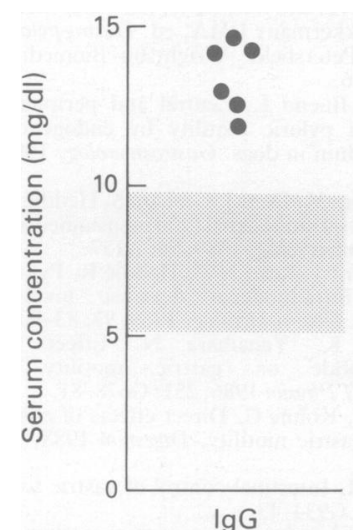

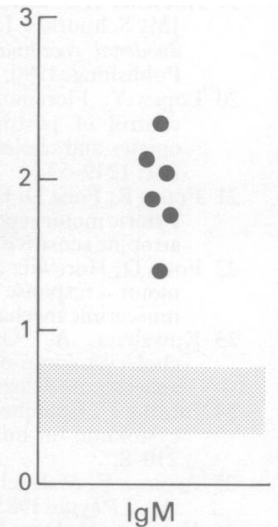

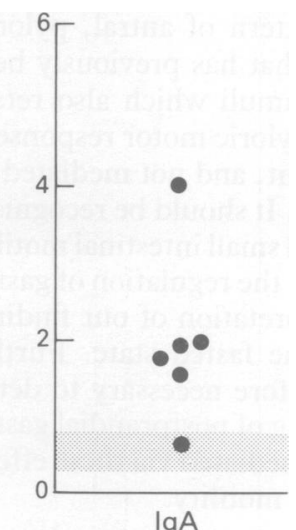

$\lg \mathrm{A}$

Figure 1: Total serum IgG, IgM, and IgA concentrations in six Gambian children with persistent diarrhoea and giardiasis. The shaded area represents the normal range for healthy control children in the Gambia.

appear to be highly susceptible to the disease. Giardiasis is especially common in infants and children and may be responsible for their retarded growth and failure to thrive.' We have recently shown that children with acute infection have an IgG and IgA response to a 57 kilodalton antigen $^{2}$ referred to as Giardia heat shock antigen ${ }^{3}$ and this is likely to play an important role in host parasite interactions as its expression is modulated not only by heat shock but also by conditions in the gastrointestinal tract. ${ }^{3}$

A recent study in the Gambia has shown that Giardia is highly prevalent in children with persistent diarrhoea and malnutrition. ${ }^{+}$The aims of the present study were to characterise the antibody response to Giardia in these children and to investigate the significance of antibodies to Giardia heat shock antigen in chronic infection.

\section{Methods}

\section{PATIENTS}

Six children from the Gambia (age 16-29 m) who had persistent diarrhoea (more than three loose stools/day, persisting for two to 52 weeks and a mean of 12 weeks) and giardiasis and failed to clear the infection even after treatment (metronidazole $25 \mathrm{mg} / \mathrm{kg} /$ day for seven days) and at follow up a year later ${ }^{+}$were included in this study. These children were severely malnourished (mean weight for height $66 \%$ of the National Centre for Health Statistics median value). Nine healthy, well nourished (mean weight for height $89 \%$ of the NCHS median value), age matched children (age 6-19 m) from the same location were included as controls. Venous blood samples were obtained from each individual and sera were stored in aliquots at $-20^{\circ} \mathrm{C}$. Ethical approval for the study was granted by the Committee on Human Experimentation of the MRC Tropical Research Unit, the Gambia.

TOTAL SERUM IMMUNOGLOBULINS

The concentrations of total IgG, IgA, and IgM in sera were determined by radial immunodiffusion. were determined by ELISA using whole Giardia 
trophozoites as antigen as described previously. ${ }^{67}$

\section{G LAMBLIA}

Portland 1 strain of $G$ lamblia was cultured axenically at $37^{\circ} \mathrm{C}$ in modified TYI-S-33 medium containing $10 \%$ newborn calf serum in roller bottles $^{8}$ and harvested at middle to late log phase as described previously. ${ }^{9}$

\section{GEL ELECTROPHORESIS AND IMMUNOBLOT ANALYSIS}

SDS-PAGE of $G$ lamblia antigens on $10 \%$ gels followed by electrophoretic transfer to nitrocellulose and immunoblotting were performed as described previously. ${ }^{2}$ Briefly, antigen strips preincubated for one hour in blocking buffer ( $5 \%$ non-fat milk powder in phosphate buffered saline $\mathrm{pH} 7 \cdot 2$, containing $0 \cdot 05 \%$ Tween 20 ) were incubated overnight at room temperature in serum samples (diluted 1:100 v/v in blocking buffer) or mouse monoclonal antibody GL2 ${ }^{9}$ that recognises Giardia heat shock antigen ${ }^{3}$ (diluted $1: 1000 \mathrm{v} / \mathrm{v}$ in blocking buffer). After four washes in phosphate buffered saline, $\mathrm{pH} 7 \cdot 2$, containing $0.05 \%$ Tween 20 , the strips were individually incubated in appropriate peroxidase conjugated anti-human IgM, IgG, or IgA or anti mouse IgG and developed. ${ }^{2}$

\section{Results}

\section{TOTAL SERUM IMMUNOGLOBULINS}

The concentrations of total serum $\operatorname{IgG}, \operatorname{IgA}$, and IgM were raised in patients: IgG median 13.5 (range 12.1-14.9) (normal range (NR) 5.4-9.7 $\mathrm{mg} / \mathrm{dl}), \operatorname{IgA~} 1.9(0 \cdot 7-4 \cdot 1)(\mathrm{NR} 0.3-0.8 \mathrm{mg} / \mathrm{dl})$ and IgM 2.0 (1.4-2.4) (NR 0.3-0.8 mg/dl) (Fig 1). The normal reference range (NR) for total IgG, IgA, and IgM were obtained from healthy control children in the Gambia. ${ }^{10}$

Figure 2: Giardia specific serum antibody titres in six Gambian children with persistent diarrhoea and giardiasis (open bars) and nine 'heathy' local controls (hatched bars). Results are represented as range and medians. ${ }^{\star} p<0.003$ Wilcoxon's rank-sum test for difference between IgM titres of patients and controls.

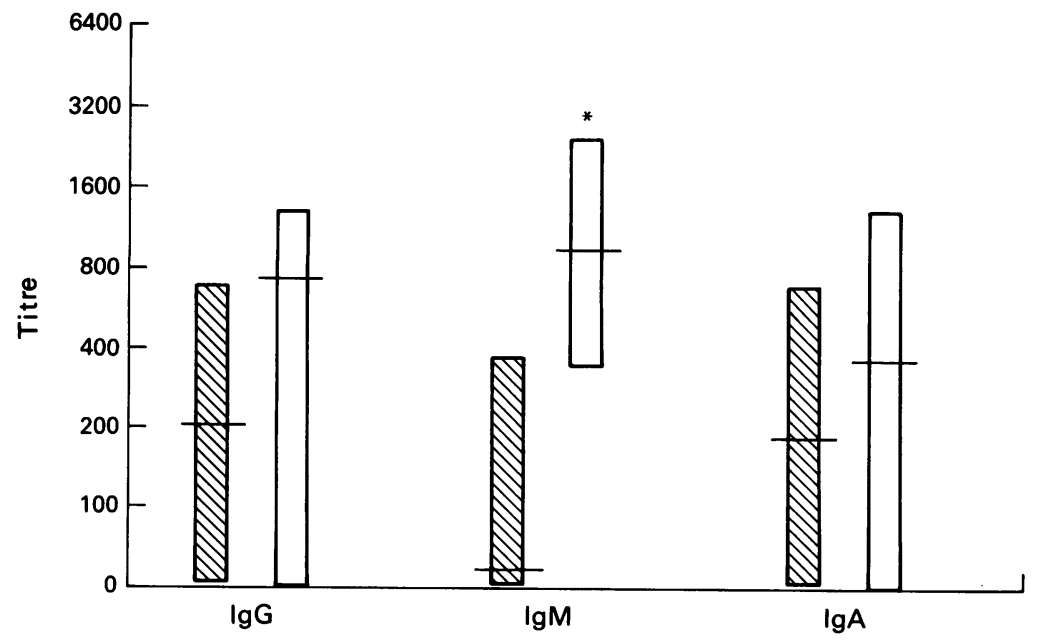

The serum antibody titres of Giardia specific $\operatorname{IgG}, \operatorname{IgA}$, and $\operatorname{IgM}$ in patients and controls are shown in Figure 2. Although patients with chronic infection had serum IgG, IgA, and $\operatorname{Ig} M$ antibodies to Giardia antigens, only the concen- trations of Giardia specific IgM were raised while those of IgG and IgA were similar to controls.

G LAMBLIA ANTIGENS RECOGNISED BY SERUM IgM, IgG, AND IgA ANTIBODIES

The antigenic determinants of the serum $\operatorname{IgM}$, IgG, and IgA responses in patients were determiend by SDS-PAGE and immunoblotting. Serum IgM antibodies gave weak reaction on blots (data not shown) suggesting that the high titres obtained by ELISA were mainly caused by $\operatorname{IgM}$ antibodies recognising native rather than SDS denatured antigens. The antigenic determinants of serum IgG and IgA responses are shown in Figure 3. Sera from all patients contained IgG antibodies that recognised Giardia heat shock antigen. A variety of antigens (100 $170 \mathrm{kDa}, 53 \mathrm{kDa}$ ) were recognised by both IgG and IgA antibodies. A variety of low molecular mass antigens $(31-45 \mathrm{kDa})$ were recognised by IgG antibodies. There were no IgA antibodies to Giardia heat shock antigen, however, in any of these children with chronic infection. In contrast, an IgG and IgA response to this antigen has been reported in children with acute infection. ${ }^{2}$

\section{Discussion}

Children with protein energy malnutrition as
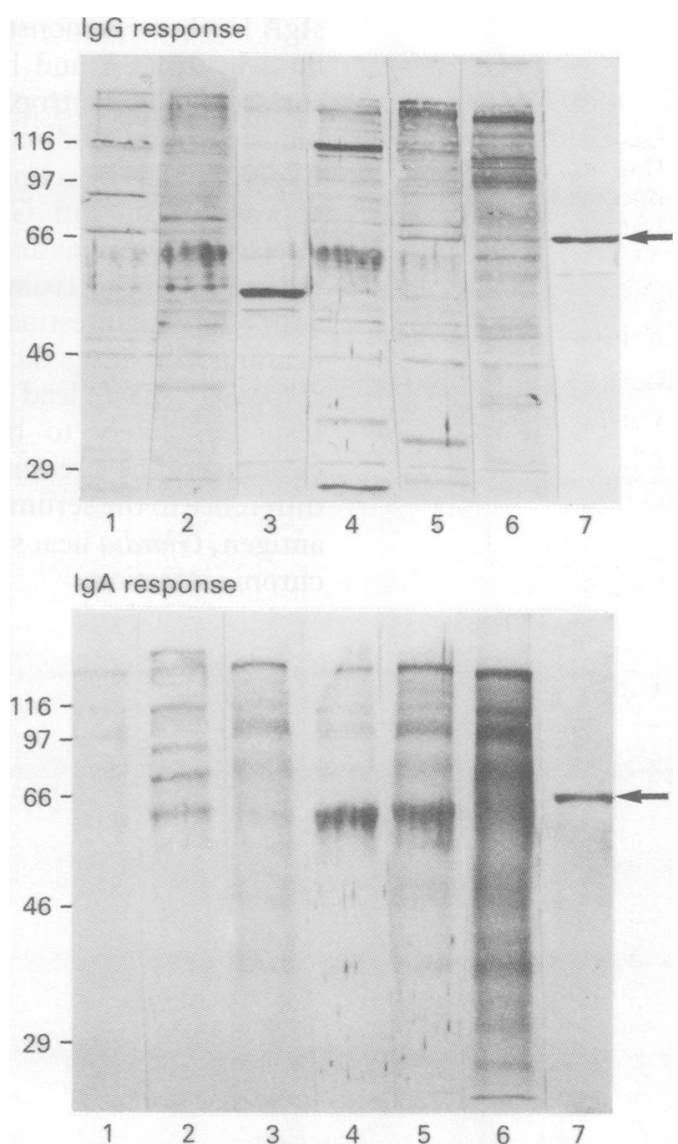

Figure 3: Detection of G Lamblia antigens recognised by IgG and IgA antibodies in sera from six Gambia children with persistent diarrhoea and giardiasis by immunoblotting (lanes 1-6). Lane 7 in each panel was probed with monoclonal antibody GL2 which recognises Giardia heat shock antigen. Numbers to the left indicate molecular mass markers. Arrows indicate the position of Giardia heat shock antigen. While all patients had IgG antibodies to Giardia heat shock antigen (top panel), IgA antibodies to Giardia heat shock antigen were absent (bottom panel). 
those in this study, are susceptible to chronic infection in spite of high concentrations of immunoglobulins," suggesting that their humoral immune response is probably defective. Analysis of the concentrations of Giardia specific serum antibodies show that only anti Giardia IgM concentrations were raised in the patients. The association of high concentrations of Giardia specific IgM, low concentrations of Giardia specific IgA and IgG and inability to clear the infection suggests that the switch from an IgM to an IgG or IgA response is defective. In addition, these patients with chronic infection unlike those who clear the infection have no IgA response to Giardia heat shock antigen. The absence of specific IgA response to Giardia heat shock antigen in patients with chronic infection suggests that the development of $\operatorname{IgA}$ antibodies to this antigen may be an important factor determining parasite clearance.

Little is known of the fundamental aspects of the immunology of chronic infection versus acute infection in giardiasis. Hypogammaglobulinemia and depressed IgG to surface antigens of Giardia have been suggested as factors contributing to chronic infection. ${ }^{12}{ }^{13}$ Secretory $\operatorname{IgA}$ is the predominant isotype of antibody in the intestinal lumen, however, and is probably more important for parasite clearance. Patients with $\operatorname{sgA}$ deficiency are more susceptible to infection by Giardia. ${ }^{14}$ The presence of specific anti Giardia sIgA has been demonstrated in human duodenal fluid by ELISA and has been detected on the surface of Giardia trophozoites in human jejunal biopsies using indirect immunofluorescence. ${ }^{15}$ Experimental infection in mice confirms the appearance of anti Giardia sIgA and IgG in intestinal secretions and clearance of the parasite relates closely to rising concentrations of these antibodies in intestinal fluid. ${ }^{16}{ }^{17}$ Hence identification of antigenic determinants of $\operatorname{IgA}$ response may lead us towards antibody responses likely to be important in parasite clearance. The present study has highlighted a difference in the serum IgA response to a Giardia antigen, Giardia heat shock antigen in acute and chronic infection.
The authors gratefully acknowledge financial support from the Wellcome Trust. MJGF is a Wellcome Trust Senior Lecturer, AMC is supported by a grant from Consejo Nacional de Ciencia y Tecnología (CONACYT), Mexico and PBS by Thrasher Fund, Tecnologia (CONACYT), Mexico and PBS by Thrasher Fund,
Salt Lake City, Utah, USA. The authors would like to thank Salt Lake City, Utah, USA. The authors would like to thank
Professor B M Greenwood, Director of MRC Laboratories, the Professor B M Greenwood, Direc
Gambia, for provision of facilities.

1 Farthing MJG. Host-parasite interactions in human giardiasis.

Qf Med 1989; 263: $191-204$.
2 Char S, Shetty N, Narasimha M, Elliot E, Macaden R, Farthing MJG. Serum antibody response in children with Giardia lamblia infection and identification of an immunodominant 57-kilodalton antigen. Parasite Immunol 1991; 13: dominant 57 . 37 .

3 Char S, Cevallos AM, Farthing MJG. An immunodominant antigen of Giardia lamblia is a heat shock protein. Biotechnol Ther 1992; 3: 151-7

4 Sullivan PB, Marsh MN, Phillips MB, Dewit O, Neale G, Cevallos AM, et al. Prevalence and treatment of giardiasis in chronic diarrhoea and malnutrition. Arch Dis Child 1991; 65: 304-6.

5 Ritzmann SE, Aguanno JJ, Sinney MA, Condon Hughes MR. Quantitation of normal and abnormal serum immunoglobulins $G, A$ and $M$ by radioimmunodiffusion nephelometry and turbimetry. In: Alan R, ed. Physiology of immunoglobulins: diagnostic and clinical aspects. New York: Liss Inc, 1982: 139-56.

6 Goka AJK, Rolston DDK, Mathan VI, Farthing MJG. Diagnosis of giardiasis by specific IgM antibody enzymelinked immunosorbent assay. Lancet 1986; ii: 184-6.

7 Goka AJK, Rolston DDK, Mathan VI, Farthing MJG. Serum IgA response in Giardia lamblia infection. Serodiag Immunother Infec Dis 1989; 3: 273-7.

8 Farthing MJG, Pereira MEA, Keusch GT. Giardia lamblia: evaluation of roller bottle cultivation. Exp Parasitol 1982; 39: $410-5$.

9 Edson CM, Farthing MJG, Thorley-Lawson DA, Keusch GT. An $88000-M_{\mathrm{r}}$ Giardia lamblia surface protein which is immunogenic in humans. Infect Immun 1986; 54: 621-5.

10 Rowland MGM. Epidemiology of diarrhea in the Gambia. In: Chen LC, Scrimshaw NS, eds. Diarrhea and malnutrition: interactions, mechanisms and interventions. New York: interactions, mechanisms and inter

11 Suskind R, Sirisinha S, Vitayasai V, Edelman R, Damrongsak D, Charupatana C, et al. Immunoglobulins and antibody response in children with protein-calorie malnutrition. $A m \mathcal{F}$ Clin Nutr 1976; 29: 836-41.

12 Taylor GD, Wenman WM. Human immune response to Giardia lamblia infection. $\mathcal{F}$ Infect Dis 1987; 155: 137-40.

13 Vinayak VK, Kumkum, Khanna R. Serum antibodies to giardial surface antigens: lower titres in persistent than in non-persistent giardiasis. $\mathcal{F}$ Med Microbiol 1989; 30: 207-12.

14 Zinneman HH, Kaplan AP. The association of giardiasis with reduced intestinal secretory immunoglobulins. Am $\mathcal{F}$ Dig Dis 1972; 17: 793-7.

15 Briaud $M$, Morichau-Beauchant $M$, Matuchansky C, Touchard G, Babin P. Intestinal immune response in giardiasis. Lancet 1981; ii: 358.

16 Snider DP, Underdown BJ. Quantitative and temporal analysis of murine antibody response in serum and gut secretions

17 Heyworth MF. Antibody response to Giardia lamblia trophozoites in mouse intestine. Infect Immun 1986; 52: 56871 . 